\title{
Evolution of the vegetation system in the Heihe River basin in the last 2000 years
}

\author{
Shoubo $\mathrm{Li}^{1}$, Yan Zhao ${ }^{2}$, Yongping $\mathrm{Wei}^{2}$, and Hang Zheng ${ }^{2}$ \\ ${ }^{1}$ School of Geography and Remote Sensing, Nanjing University of Information Science \& Technology, \\ Nanjing, 210044, China \\ ${ }^{2}$ School of Earth and Environmental Sciences, the University of Queensland, 4072 Brisbane, Australia \\ Correspondence to: Shoubo Li (lishb@nuist.edu.cn) and Yan Zhao (yanzhao.cas@gmail.com)
}

Received: 14 September 2016 - Discussion started: 9 January 2017

Accepted: 17 July 2017 - Published: 28 August 2017

\begin{abstract}
The response of vegetation systems to the longterm changes in climate, hydrology, and social-economic conditions in river basins is critical for sustainable river basin management. This study aims to investigate the evolution of natural and crop vegetation systems in the Heihe River basin (HRB) over the past 2000 years. Archived Landsat images, historical land use maps and hydrological records were introduced to derive the long-term spatial distribution of natural and crop vegetation and the corresponding biomass levels. The major findings are that (1) both natural and crop vegetation experienced three development stages: a pre-development stage (before the Republic of China), a rapid development stage (Republic of China - 2000), and a post-development stage (after 2000). Climate and hydrological conditions did not show significant impacts over crop vegetation, while streamflow presented synchronous changes with natural vegetation in the first stage. For the second stage, warmer temperature and increasing streamflow were found to be important factors for the increase in both natural and crop vegetation in the middle reaches of the HRB. For the third stage, positive climate and hydrological conditions, together with policy interventions, supported the overall vegetation increase in both the middle and lower HRB; (2) there was a significantly faster increase in crop biomass than that of native vegetation since 1949, which could be explained by the technological development; and (3) the ratio of natural vegetation to crop vegetation decreased from 16 during the Yuan Dynasty to about 2.2 since 2005. This ratio reflects the reaction of land and water development to a changing climate and altering social-economic conditions at the river
\end{abstract}

basin level; therefore, it could be used as an indicator of water and land management at river basins.

\section{Introduction}

Natural vegetation plays a key role in maintaining functions of catchment ecosystems, including contributions to goods, services, and ecosystem biodiversity at arid and semiarid river basins (Ahlström et al., 2015; Feng et al., 2013; Kefi et al., 2007). With the rapid population growth, an increasing amount of water has been allocated worldwide to support human activities, particularly for agricultural irrigation, whereas water for natural vegetation, wetlands, and other catchment ecosystems might have been compromised. Consequently, natural vegetation systems in water-limited regions have been degraded, and salinization and desertification have been reported repeatedly (Huang et al., 2015; Li et al., 2007; Su et al., 2007; Xue et al., 2015). An understanding of the development of natural vegetation under different water availability conditions, and its interactions with the human crop system, is vital for sustainable river basin management.

There are an overwhelming number of studies on the impact of land use and land cover changes driven by either human activities or climate changes, on the catchment hydrological regime and on the water cycle (Esteban and Albiac, 2011; Ian and Reed, 2012; Leggett et al., 2003; Xue et al., 2015). However, few studies have investigated how the vegetation system evolved in response to the changes in water regimes at the basin scale. In the last decade, an increasing 
number of studies have contributed to the knowledge of allocating the limited water resources among different ecosystems in river basins to balance the economic development and environmental sustainability (Wang et al., 2007). However, most of these studies were carried out within a short time range, either to identify the rationality of water allocation scheme reform (Cheng, 2002; Yang et al., 2003) or to test the effectiveness of ecological restoration projects (Thevs et al., 2015). Long-term change study in vegetation systems in response to significant alterations in climate, hydrology, and social-economic conditions is lacking in the current literature (Sivapalan et al., 2012).

The knowledge gap identified above happened partly due to the unavailability of long-term instrumental data on vegetation and hydrological change at the basin scale. With the rapid development of remote-sensing techniques, images acquired from multiple satellite platforms provide an ideal method to track the landscape changes at river basins in the past 5 decades (Nian et al., 2017; Beuchle et al., 2015). Among a mass of the remote-sensing-based metrics to characterize vegetation systems, spatial extent, normalized differential vegetation index (NDVI) and biomass are commonly recognized as the most effective indices which have been widely applied in spatial analysis of landscape ecosystems (Pettorelli et al., 2005; Pinsky and Fogarty, 2012). For historical periods (previous years with no remotely sensed data), emerging approaches including dendrochronology, ice core analysis, and other empirical methods have been applied to reconstruct eco-hydrological elements and their long-term variations (Turner et al., 2007; Lowry and Morrill, 2011). Several studies tried to reconstruct historical cultivated vegetation systems, but relatively little attention has been paid to natural vegetation distributions in historical periods $(\mathrm{Hu}$ and Li, 2014; Xie et al., 2013; Ramankutty and Foley, 1999). Moreover, factors and mechanisms driving vegetation evolution have largely remained neglected.

The Heihe River basin (HRB), located in arid northwestern China, is an important part of the ancient Silk Road established in the Han Dynasty (206 BC-AD 220). It was also a trade center between China and western countries, which facilitated cultural and economic exchange for approximately 1500 years. The HRB is a typical inland river ecosystem, which includes natural vegetation, irrigated crop, desert and terminal lakes. The middle course of the basin has an agricultural history over more than 2000 years, while the lower reaches are located at the alluvial fan - supporting local human civilization and ecosystem development (Fu et al., 2014). Increasing agricultural development and changing climate and hydrology over the past 2000 years have significantly changed use of land and water resources and have modified the catchment vegetation system (Lu et al., 2015a; Zhao et al., 2016). More specifically, several decadal-scale studies have provided quantitative descriptions of agricultural and natural vegetation changes responding to the water transfer project implemented since 2000, which effec- tively prevented further ecosystem degradation (Zhao et al., 2016; Lu et al., 2015c). Within a centurial scale, Nian et al. (2017) found that the rapid expansion of cultivated land was the primary force causing serious ecological deterioration in the HRB. However, information about long-term vegetation changes responding to the rise and fall of civilizations, as well as the changed climate and hydrology conditions, is currently lacking. Such information is crucial for an understanding of the ecosystem's health and for promoting sustainable management in the basin.

The present study aims to understand the vegetation evolution in the HRB over the past 2000 years, for which both natural and crop vegetation are considered. The specific objectives of the present study are (1) to determine the area and biomass of vegetation using remote-sensing imagery for recent years (since 1987); (2) to reconstruct vegetation distribution and biomass levels for previous periods (before 1987) and (3) to determine potential factors for vegetation evolution. It is expected that the methods developed and the findings obtained from this study could assist in achieving an understanding of how current ecosystem problems emerged in the past and what their implications can be for future river basin management.

\section{Material and methods}

\subsection{Study area}

The HRB is the second largest inland river basin in China, which stretches between $38-43^{\circ} \mathrm{N}$ and $98-102^{\circ} \mathrm{E}$ (Fig. 1). The middle and lower courses of the HRB contain several types of landscape, including river delta plains, terminal lakes, mobile dunes and semi-mobile dunes, and low mountains and hills. The unused land such as the desert, Gobi and bare land accounts for more than $75 \%$ of the river basin, while cropland only takes up $4 \%$ (according to the land cover map of 2011; data available at the WestDC database $\mathrm{http}: / /$ westdc.westgis.ac.cn/). The rest of the landscape is distributed with natural oases. The main vegetation types in these regions are dry steppes and shelter forests.

The terrain in the HRB gradually tilts from southwest to northeast. The altitude of the area ranges from about 820 to $1100 \mathrm{~m}$. The region has a typical continental arid climate characterized by frequent wind, scarce rainfall, abundant sunshine and intensive evaporation. The average annual temperature in this area over the last 3 decades is $8.3^{\circ} \mathrm{C}$ (with remarkable seasonal variations). Temperatures can decrease to $-37.6^{\circ} \mathrm{C}$ in winter months and reach up to $43.1{ }^{\circ} \mathrm{C}$ in summer months (the highest temperature normally occurs around July). The annual average pan evaporation in the Ejina oasis is 3749 to $4132 \mathrm{~mm} \mathrm{yr}^{-1}$, which is much higher than the mean annual precipitation (ranging from 7 to $101 \mathrm{~mm} \mathrm{yr}^{-1}$ ), with substantial interannual variations over the past 3 decades. 


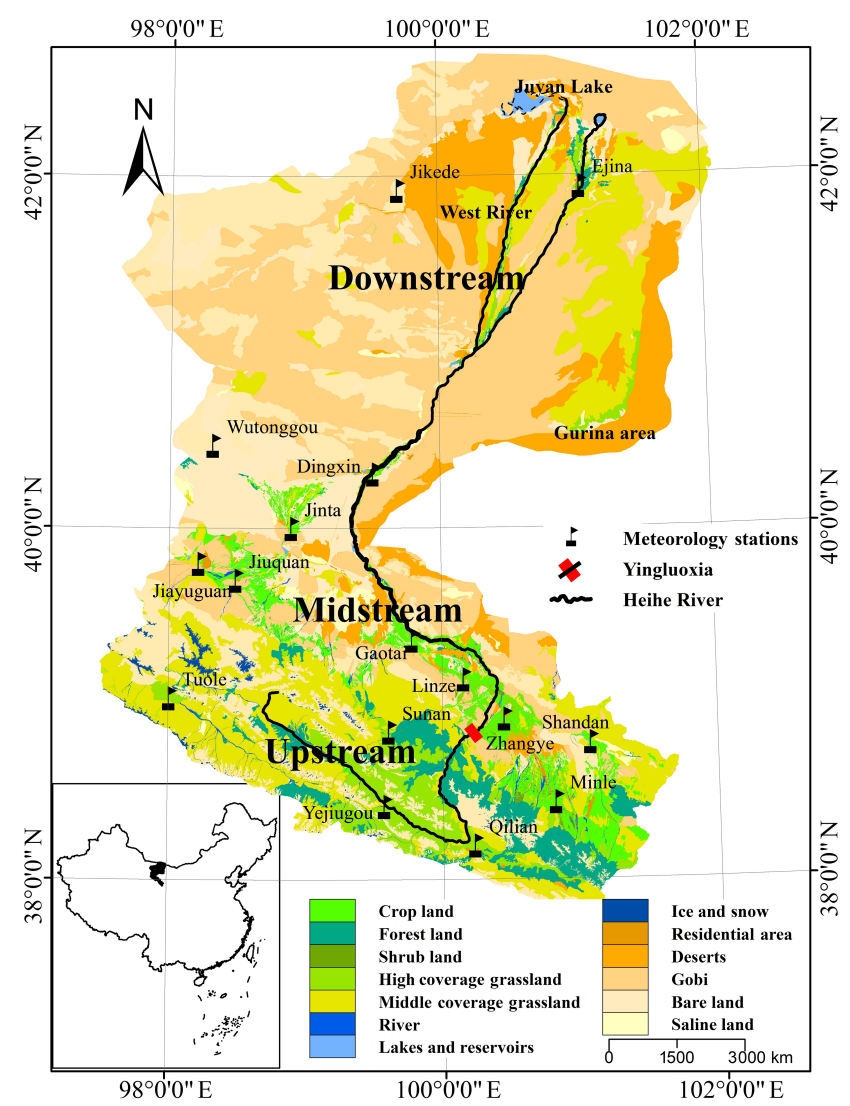

Figure 1. Location of the Heihe River basin (HRB). Land cover data (2011) are available at the WestDC database (http://westdc. westgis.ac.cn/).

River inflow from the northern Qilian Mountains constitutes the primary water source for the river basin. It makes the HRB an important grain production base and the region has experienced intensive agricultural activities to meet the grain demands of military events since the Han Dynasty (121 BCAD 220) (Xie et al., 2013). Nowadays, the midstream is still one of the most important agricultural belts in northwestern China. However, the increasing water abstraction for irrigation, along with increasing usage for domestic purposes in middle reaches, has substantially consumed the available water supply for downstream systems over the past several decades. Consequently, Juyan Lake shrank dramatically in the last 100 years, and dried up in 1992 (eastern Juyan Lake). Since the late 1990s, the Chinese government has implemented a series of policies to secure the required amount of water for sustaining the ecosystems in lower river courses and to avoid further degradations. In 2002, Juyan Lake (east) started to retain water again, which was taken as an important sign of ecosystem recovery (Nian et al., 2017).

\subsection{Study period}

We selected the past 2000 years as our study period, which started from the Han Dynasty (206 BC-AD 220) (Table 1). This timescale covered several ancient dynasties of China, the Republic of China (RC), and the Peoples' Republic of China. The period has experienced dramatic changes in climate, land use, runoff, management policy, population, social and ecological developments. All these factors could contribute to changes in water cycles within the river basin and can, therefore, influence vegetation distributions.

\subsection{Determining vegetation distribution and estimating vegetation biomass}

\subsubsection{Landsat image preprocessing}

Landsat images have been used to derive vegetation distribution and biomass since the 1980s. Five Landsat scenes (path/row 133/31, 133/32, 133/33, 134/31, and 134/32) for each year were required to cover the area. The collected images covered the timescale ranging from 1987 to 2015, except for 1989 and 1996, when there were no high-quality images. Most of these images were acquired from June to October to represent the growing season for crops and natural vegetation in the study area.

The Landsat datasets containing digital numbers (DNs) were downloaded from the United States Geological Survey (USGS) Earthexplorer website (http://earthexplorer. usgs.gov/). The DN values were converted into top-ofatmosphere (TOA) reflectance using the radiometric gain and offset values associated with each Landsat image. Then a quick atmosphere correction (QUAC) method was adopted to account for atmospheric scattering and to derive land surface reflectance. NDVI was then calculated using the red and near-infrared bands for each year.

As demonstrated with MODIS NDVI series (Fig. 2), natural and crop vegetation presented significant phenology cycles. Since the collected annual Landsat images were acquired at different dates (sometimes in different months) of a year, the above calculated NDVI values might have included these seasonal variations. To compensate for this effect, we used the MODIS NDVI profile in 2013 to calibrate the Landsat NDVIs to an annual maximum NDVI using a linear interpolation algorithm. Specifically, with the knowledge of the acquisition date of a Landsat image for a specific year, the ratio of the MODIS NDVI for that date to the maximum MODIS NDVI was calculated, and this ratio was applied to the Landsat-derived NDVI to calculate the maximum NDVI for that year. The method could be presented with the following equation:

$\mathrm{NDVI}_{\mathrm{L}-\max }=\mathrm{NDVI}_{\mathrm{L} i} \times \mathrm{NDVI}_{\mathrm{M}-\mathrm{max}} / \mathrm{NDVI}_{\mathrm{M} i}$,

where "L" stands for Landsat, "M" stands for MODIS, and " $i$ " stands for the date when the Landsat NDVI needs cali- 
Table 1. Major dynasties during the selected study period (Lu et al., 2015c).

\begin{tabular}{lll}
\hline Dynasty & Period & Main production \\
\hline Han Dynasty & 206 BC-AD 220 & Agriculture \\
Wei-Jin Era & AD 220-AD 420 & Animal husbandry \\
Sui-Tang Dynasty & AD 581-AD 907 & Agriculture \\
Yuan Dynasty & AD 1271-AD 1368 & Animal husbandry \\
Ming Dynasty & AD 1368-AD 1644 & Agriculture \\
Qing Dynasty & AD 1644-AD 1912 & Agriculture \\
Republic of China (RC) & AD 1912-AD 1949 & Agriculture \\
The Peoples' Republic of China (PRC) & Since AD 1949 & Agriculture \\
\hline
\end{tabular}

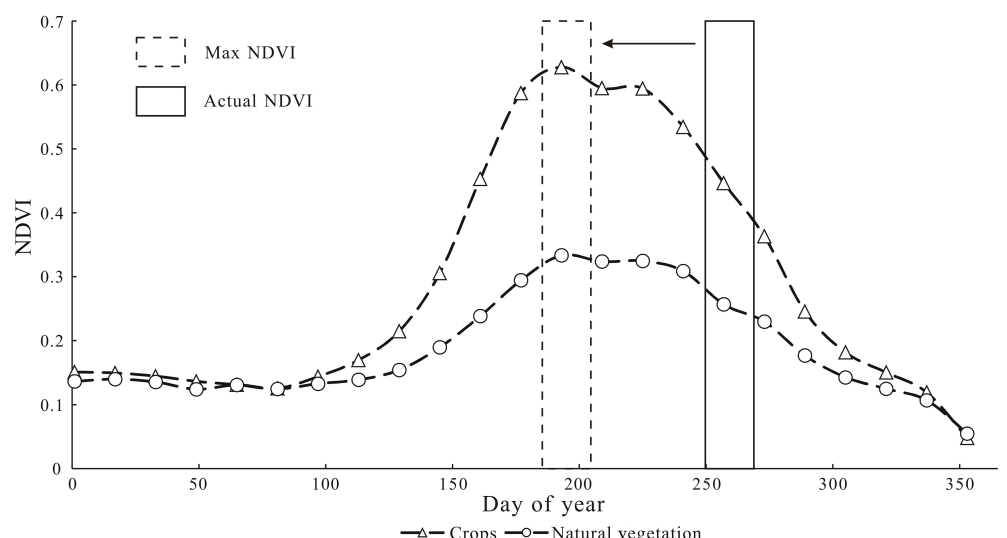

Figure 2. NDVI profile for natural vegetation and crops in 2013. The rectangles indicated the scheme of the calibrated actual Landsat NDVI (solid rectangle) to the annual maximum NDVI (dashed rectangle).

bration. The MODIS $250 \mathrm{~m}$ NDVI product (i.e., MOD13Q1) was applied in this procedure. Only the data of 2013 were used with the consideration that annual vegetation growth would follow a similar phenology cycle. Thus, it is necessary to use the 2013 NDVI series to calibrate the Landsat NDVI in extra years without causing significant uncertainties in the final results.

\subsubsection{Determining vegetation areas and biomass since the 1980s with satellite images}

Two rounds of threshold analysis were applied to determine natural and crop vegetation distributions in the HRB since the 1980s. Through an analysis of the NDVI histogram distribution characteristics, 0.12 was selected as the first threshold value to mask out non-vegetation landscapes, including water surfaces, deserts, residential areas and other bare surfaces. Then, the second round of threshold analysis was introduced to separate crop vegetation from natural vegetation according to their phenology differences (Fig. 2). In short, we randomly sampled the vegetation maps and derived the average NDVI levels for natural and crop vegetation, respectively. Then, 0.35 was set as the second threshold to separate crop $(\geq 0.35)$ and natural $(<0.35)$ vegetation. A most recent land cover map (i.e., 2011) created by the Cold and
Arid Regions Environmental and Engineering Research Institute, Chinese Academy of Sciences, was introduced to assist in identifying vegetation types. The preliminary results were first overlaid with each year's Landsat images to check the accuracy. The threshold for the year was adjusted when it presented significant errors in the classification results. In addition, the results in 2000 and 2011 were verified with a set of land use maps (2000, 2011) obtained from the WestDC database (http://westdc.westgis.ac.cn/). A detailed scheme of inter-comparison of land cover maps between this study and existing results were detailed in Zhao (2016). Overall, the two datasets presented substantial consistency where kappa coefficients $(k)$ were 0.7206 and 0.6731 for 2000 and 2011 . Areas of natural and crop vegetation for each year were calculated by summing areas of every small patch of natural and crop vegetation, respectively.

To study the vegetation development and water usage, biomass for natural and crop vegetation was calculated using the NDVI. Regression models established by Zhao et al. $(2007,2010)$ for the HRB were adopted. In Zhao's research, herbaceous biomass was measured by means of dry biological weighing methods and the field measured biomass for natural and crop vegetation showed high correlation with NDVI $(R>85 \%$ and $p<0.01)$. Therefore, the following equations were established for natural and crop vegetation, 
respectively.

Biomass $\left(\mathrm{g} \mathrm{m}^{-2}\right)=327.4 \times \mathrm{NDVI}+102.29$ for natural vegetation (Zhao et al., 2007)

Biomass $\left(\mathrm{g} \mathrm{m}^{-2}\right)=1789 \times \mathrm{NDVI}+559.68$ for crops

(Zhao et al., 2010)

These two equations were applied to the $\mathrm{NDVI}_{\mathrm{L}-\max }$ series created in Sect. 2.3.1 to obtain the crop and natural vegetation biomass since the 1980s in the HRB.

\subsubsection{Historical vegetation distributions and biomass levels}

The crop and natural vegetation areas in previous dynasties (Table 1) were derived from Lu et al. (2015a)'s results. In Lu at al. (2015a)'s study, historical cropland was reconstructed based on population, grain yield and ancient ruin distributions. Natural vegetation distributions were estimated based on the assumption that people tended to select natural oases (grassland and forest) rather than desert for reclamation in historical periods because the former have better water and soil conditions in these arid regions, while the abandoned croplands desertified. Thus, natural vegetation for previous dynasties could be evaluated based on the changes in cropland between the previous and current dynasties ( $\mathrm{Lu}$ et al., 2015a; Xie et al., 2013, 2016).

To estimate historical vegetation biomasses, we first established the relationship between biomass and several variables which have a potential impact on vegetation development. The candidate variables include temperature $(T)$, river flow from the upstream $(Q)$, river flow to Juyan Lake $\left(Q_{1}\right)$, groundwater recharge $\left(Q_{\mathrm{g}}\right)$ and precipitation $(P) . T$ and $P$ records were collected from the surrounding weather station (Fig. 1). River flow to Juyan Lake was determined according to the records measured at Ejina station. Streamflow through Yingluoxia gauge station stands for the total upstream inflow to the study area $(Q)$. Groundwater reserve data were obtained from the government statistics yearbook (Mi et al., 2015). The component of streamflow consumed for vegetation developments $(\Delta Q)$ was then determined by deducting $Q_{1}$ and $Q_{\mathrm{g}}$ from $Q$. With this established database, a stepwise regression method was introduced to explore relationships between biomass (biomass for natural vegetation, biomass for crops and the total biomass) and the selected hydrological and climatic metrics. As indicated by the regression model, the significant relationship between total biomass and $T$ and water supply $(\Delta Q)$ was found as listed below $\left(R^{2}=0.612\right)$.

Total biomass $=39.246 \cdot T+9.312 \cdot \Delta Q-345.671$

$\Delta Q=Q-Q_{1}-Q_{\mathrm{g}}$

We then applied Eq. (4) to estimate historical total biomass levels using the corresponding $(T, \Delta Q)$ settings. Specifi- cally, historical $T$ was derived from paleoclimate records reported by Yang et al. (2002). $Q$ estimations by Sakai et al. (2012) based on glacier mass balance analysis were adopted. Since the spatial extent of the lake did not change considerably in historical periods, $Q_{1}$ was assumed to be equal to evaporations from the lake surface which could be derived from public articles (Xiao and Xiao, 2008); $Q_{\mathrm{g}}$ was set to be 0 based on the assumption that groundwater level did not change over the historic periods when agricultural activities were relatively small (Wang et al., 2009).

Unlike crop biomass, which was largely influenced by technological development, the biomass of natural vegetation was considerably less influenced by human activities. Therefore, we assumed that biomass density for natural vegetation in the region did not change over the study period. According to the Landsat-based results for the past 30 years, the average biomass density for natural vegetation was stable at about $190 \mathrm{~g} \mathrm{~m}^{-2}$ and this value was applied to historical vegetation maps to get the corresponding biomass estimations for natural vegetation. Crop biomass was then estimated by deducting the component for natural vegetation from the total biomass estimations.

\subsection{Determination of potential driving factors for vegetation developments}

Hydrological variables including $Q, \Delta Q$ and climatic variables including $P$ and $T$ (Lan, et al. 2004) were related to spatial extents and biomass levels of natural and crop vegetation through multiple linear regression analysis to assess whether or not there were any significant relationships. The regression analysis was applied to the dataset covering the entire study period and the sub-dataset since the 1980s (derived from Landsat), respectively, to check the robustness of the relationship. The analysis was performed with the IBM SPSS Statistics software package (version 20.0).

\section{Results}

\subsection{Spatial and temporal variations in vegetation distribution in the past 2000 years}

The reconstructed natural (green) and crop (red) vegetation distributions spanning the past 2000 years are shown in Fig. 3. Historic maps (before 1987) were derived from $\mathrm{Lu}$ et al. (2015a)'s results and maps after that were interpreted from Landsat images. The spatial extent of crop vegetation in both the midstream and downstream of the HRB has changed significantly over the study period. Distribution of crops was focused within the Ejina and Jinta in the Han Dynasty. Since the Tang dynasty, the major crop distribution has shifted to the regions surrounding the current Zhangye, while cropland in lower reaches has largely decreased. Since the establishment of the PRC, the crop vegetation has increased at a high rate, especially in the midstream. As for natural vegetation, 

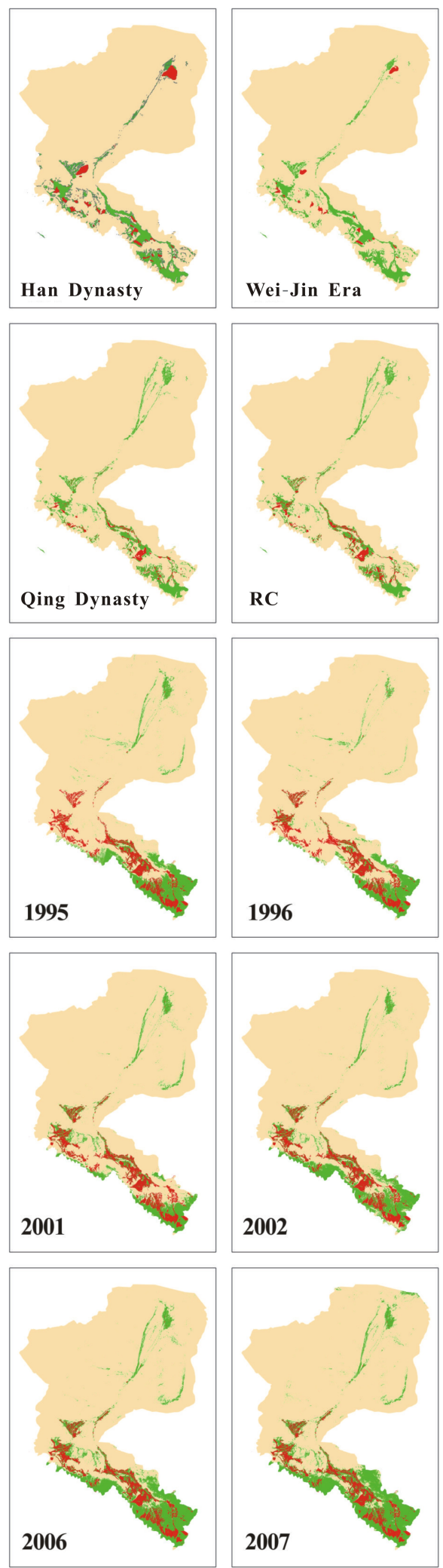
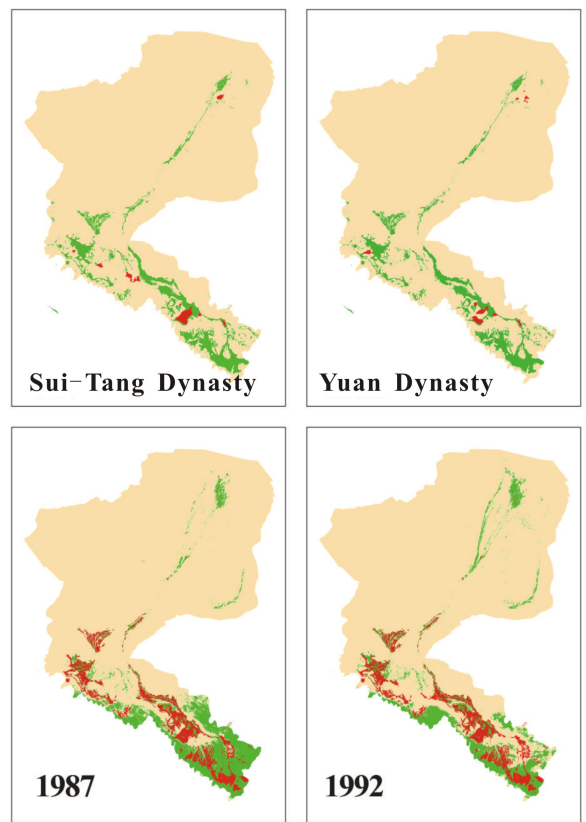
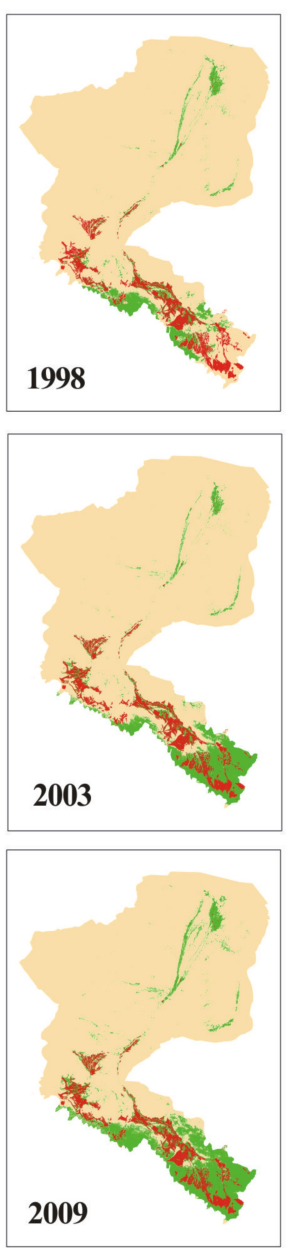
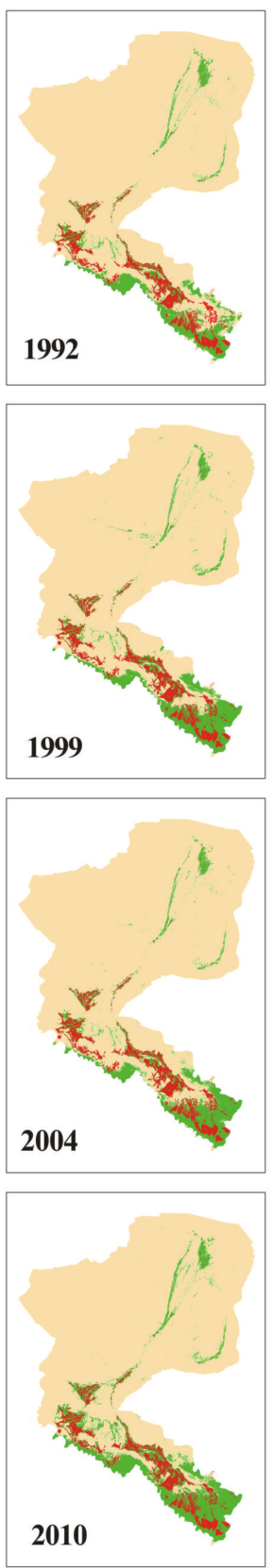
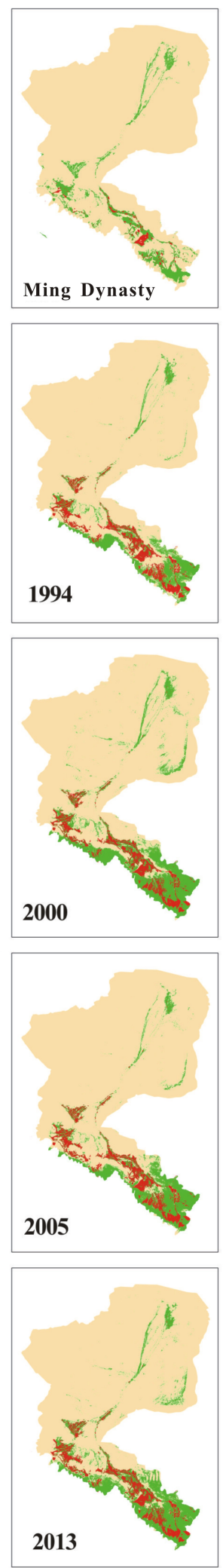

Crop Natural vegetation

Figure 3. Reconstructed natural (green) and crop (red) vegetation distributions in the past 2000 years. Historic maps (before 1987) were derived from Lu's results (Lu et al., 2015a) and maps after that were interpreted from Landsat images. 


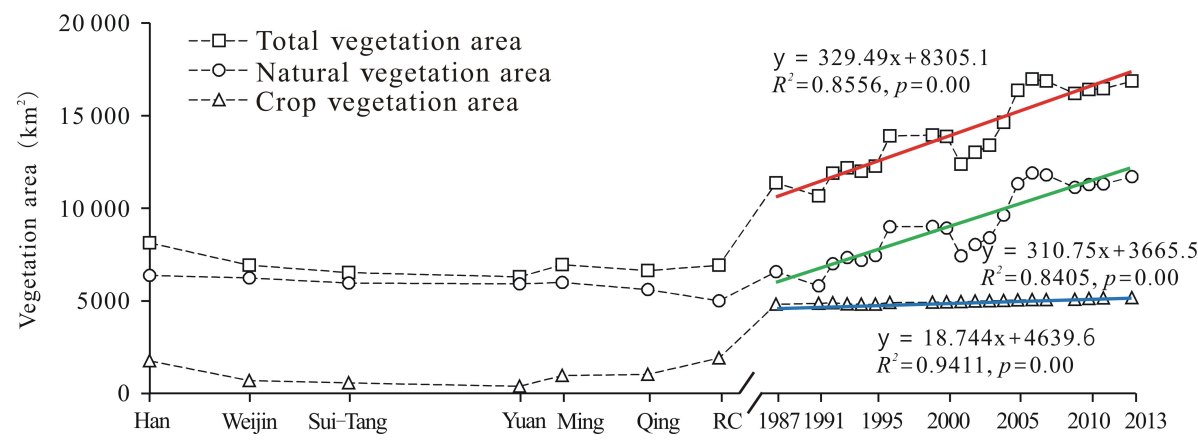

Figure 4. Temporal variations in total vegetation areas (square), natural vegetation (circle) and crops (triangle). It should be noted that data after 1987 reflect the results after applying a 3-year moving average to reduce the annual fluctuations.

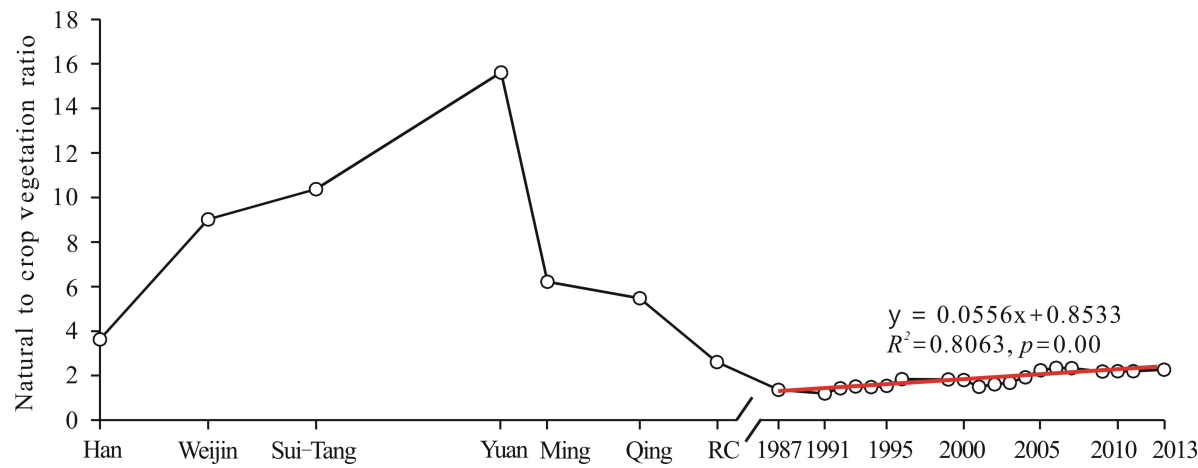

Figure 5. Changes in ratios between the areas of natural vegetation to crop vegetation in the past 2000 years.

prior to the Yuan Dynasty, natural vegetation in the downstream was primarily distributed along the East River channel. Vegetation distributions along the West River have been observed since the Ming Dynasty. For modern China (after the RC), natural vegetation presented an overall decrease from the RC to the 1980s and 1990s. A recovering trend has been observed since the 2000s. There were few changes in natural vegetation distribution in the midstream regions in ancient dynasties (prior to the Qing Dynasty). From 1949 to 2000, natural vegetation in the midstream basin has significantly increased, with substantial interannual fluctuations. After 2000, vegetation distribution has been relatively stable at a high level.

The temporal variation of vegetation areas over the past 2000 years is presented in Fig. 4. The total vegetation area increased by $8732 \mathrm{~km}^{2}$ during the studied period. Historically, total vegetation within the HRB experienced a slight decrease, from about $8122 \mathrm{~km}^{2}$ in the Han Dynasty to about $6918 \mathrm{~km}^{2}$ in the Republic of China. Natural vegetation for this period constantly decreased by $21 \%$ to only $5000 \mathrm{~km}^{2}$. Cropland for the same period presented more variations: it had a large spatial extent in the Han Dynasty at about $1755 \mathrm{~km}^{2}$, and then gradually decreased to about $379 \mathrm{~km}^{2}$ in the Yuan Dynasty. From the Ming Dynasty onward, it started to increase again and reached a peak of $1917 \mathrm{~km}^{2}$ in the Republic of China. Situations were different in the period of modern China. Total vegetation area increased from about $6918 \mathrm{~km}^{2}$ to $11362 \mathrm{~km}^{2}$ in 1987 and to $13863 \mathrm{~km}^{2}$ in 2000 with an increasing rate of $2 \%$ per year, while the crops substantially increased by about $150 \%$ to $4939 \mathrm{~km}^{2}$ in 2000 . In the same period, natural vegetation has also substantially increased, from about 6559 in 1987 to about $8924 \mathrm{~km}^{2}$ in 2000 . After 2000, the increasing rate of the crop area has decreased from $3 \%$ per year to $0.3 \%$ per year, while the natural vegetation has substantially increased to about $11691 \mathrm{~km}^{2}$ in 2013 , resulting in the total vegetation area steadily increasing to $16854 \mathrm{~km}^{2}$ in 2013 .

The ratio of natural vegetation area to crop vegetation area has varied over the past 2000 years (Fig. 5). The ratio, to some extent, has reflected the relationship and interactions between the two vegetation systems. As demonstrated in Fig. 5, although small in scale, natural vegetation occupied a major portion of the vegetation in this area in the Han Dynasty, and it substantially increased until the Ming Dynasty, when the ratio peaked at 16 . The increased ratio during this period could be attributed to the decreased amount of farming activities (Figs. 3 and 4). As agriculture started to boom since the Qing Dynasty, the ratio decreased significantly to about 1.4 in the Republic of China. Afterward, the ratio showed a constant increase, with a rate of 0.06 per year $\left(R^{2}=0.8063\right)$. Overall, the ratio of natural vegetation area to crop vegetation area during the modern China period was 
relatively stable compared to the great historic fluctuations, and it has stabilized at around 2.2 since 2005 .

\subsection{Changes in vegetation biomass over the past 2000 years}

Using the Landsat-derived biomass estimations and the corresponding hydrological and climatic records, we created the relationship between biomass and $T$ and $\Delta Q$ as demonstrated in Eq. (3). The relationship was applied to the longterm $T$ and streamflow records to derive historic biomass estimations. As shown in Fig. 6, biomass in natural vegetation in historic periods (prior to the Republic of China) experienced a decrease by $20 \%$ and the biomass of crop underwent a decrease before the Tang Dynasty and increased after it. Since the Republic of China, biomass in natural vegetation has shown a gradual increase, from about $95 \times 10^{4}$ to $159 \times 10^{4} \mathrm{t}$ in 2000 . After 2000, the upward trend continued with a higher increasing rate. For crops, the biomass presented a sharp increase by about 4 times from the RC to the 1980s. A slight increasing trend in the past 30 years was observed. The average biomass per unit area of natural vegetation was stable, while the average biomass per unit area of crop increased by 2.2 times over the past 2000 years. The average biomass per unit area of crop increased by about $180 \%$ since the PRC.

\subsection{Impacts of hydrological and climatic variables over vegetation development in the past 2000 years}

The regression analysis between vegetation development and hydrological and climatic variables shows that both $T$ and $\Delta Q$ present an overall positive effect on natural and crop vegetation distributions (Fig. 7a and b). From a holistic perspective, $T$ showed a significant impact over natural vegetation expansion, while its effects on crops were quite limited. Meanwhile, $\Delta Q$ exerted similar effects on both natural $\left(R^{2}=0.6016, p=0.00\right)$ and $\operatorname{crop}\left(R^{2}=0.9188\right.$, $p=0.00)$ vegetation development over the past 2000 years. It is also found that $T$ showed significant positive impacts over both natural $\left(R^{2}=0.7684, p=0.00\right)$ and $\operatorname{crop}\left(R^{2}=0.6836\right.$, $p=0.00)$ vegetation during the past 3 decades with instrumental data (Fig. $7 \mathrm{c}$ and d). Similar for $\Delta Q$, it alone contributed about 77 and $60 \%$ of the area expansion since the 1980 s for natural ( $p=0.00)$ and crop $(p=0.00)$ vegetation, respectively. A multiple factor regression analysis shows that increasing $T$ and $\Delta Q$ could explain over $90 \%$ of the vegetation development (i.e., $96.0 \%$ for natural vegetation and $91.7 \%$ for crops). Although the development of vegetation did not show an evident relationship with precipitation, there were some years during which vegetation area was less than other years in last 30 years, for example, 1992 and 2001, which may be due to the interannual variations of precipitation.

\section{Discussion and conclusions}

This paper presented an empirical study of the evolution of vegetation systems in the HRB over the past 2000 years. The vegetation system was categorized into natural vegetation and crop vegetation. The area and biomass of each vegetation system since the 1980s were estimated based on the remotesensing image data. For the historical periods, the area and biomass of each vegetation system were reconstructed based on the relationship between the area and biomass of the vegetation system and the climatic and hydrological variables in the last 30 years with the measured data. Some major research findings and their implications for future research and river basin management practice will be discussed below.

Both natural and crop vegetation development in the HRB, based on the change in area and biomass in the past 2000 years (Figs. 3, 4 and 7), can be divided into three stages: (1) a pre-development stage (before RC), (2) a rapid development stage (RC-2000), and (3) a post-development stage (after 2000). In the pre-development stage, agriculture was developed at a low level, resulting in a high natural to crop vegetation ratio. Water did not limit agricultural activities. No significant contributions from climatic $(T$ and $P$ ) and hydrological $(Q)$ variables were observed in the regression analysis either. The small-scale and decreasing crop vegetation distributions could be attributed to the small population size. Previous studies have reported that agricultural activities for these periods were primarily aimed at meeting political and military needs (Xie et al., 2013). However, the slightly decreased streamflow (Sakai et al., 2012) might be a key contributor to the overall decreased natural vegetation prior to the Ming Dynasty, as evidenced by the synchronous change between vegetation area and streamflow records (Figs. 4 and 8) and the regression relationship between the two (Fig. 7a). In the Ming Dynasty, temperature dropped while streamflow slightly recovered (Fig. 8). The decreased evapotranspiration and increasing water availability might have stimulated vegetation growth along the river channel as demonstrated in Fig. 3, especially for the natural vegetation distributions along the West River.

After the RC (the rapid development stage), crop area in the HRB experienced a rapid increase as food security had been the priority agricultural policy in China. The government encouraged farmers to reclaim unused land and promoted numerous irrigation projects (Lu et al., 2015b). In addition, the shelter forest system established after the 1980s not only protected the existing cropland, but also made it possible to change the desert surrounding the oasis into tillable lands. The consistently increasing streamflow due to the warm climate (more notably for the past 2 decades) and therefore increased precipitation and snow melting in the upper reaches might have supported the expansion of crop vegetation. The increased streamflow might have supported the rapid natural vegetation growth in the middle reaches as well, either through direct watering of the riverside vegeta- 


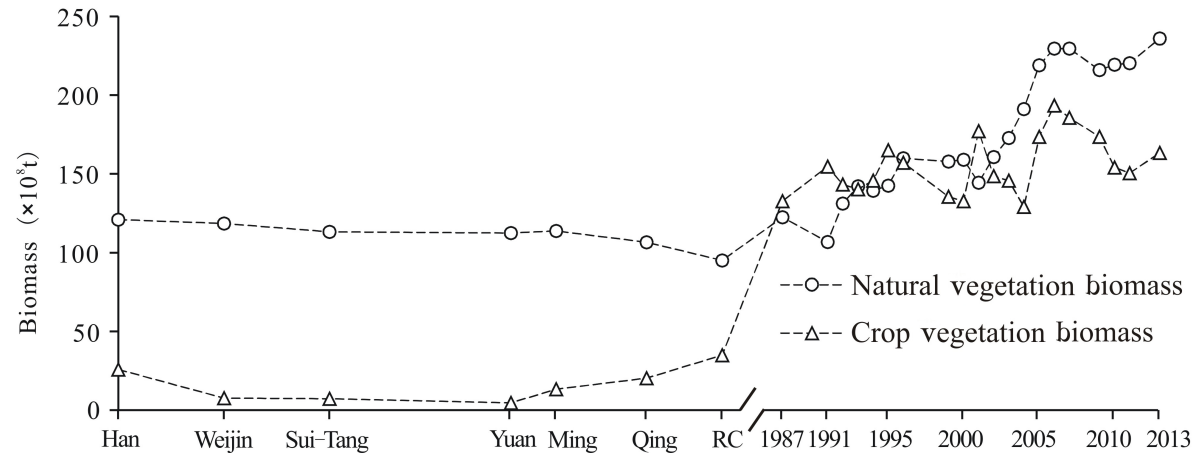

Figure 6. Temporal variations in the biomass of natural vegetation (triangle) and crops (circle) over the past 2000 years.
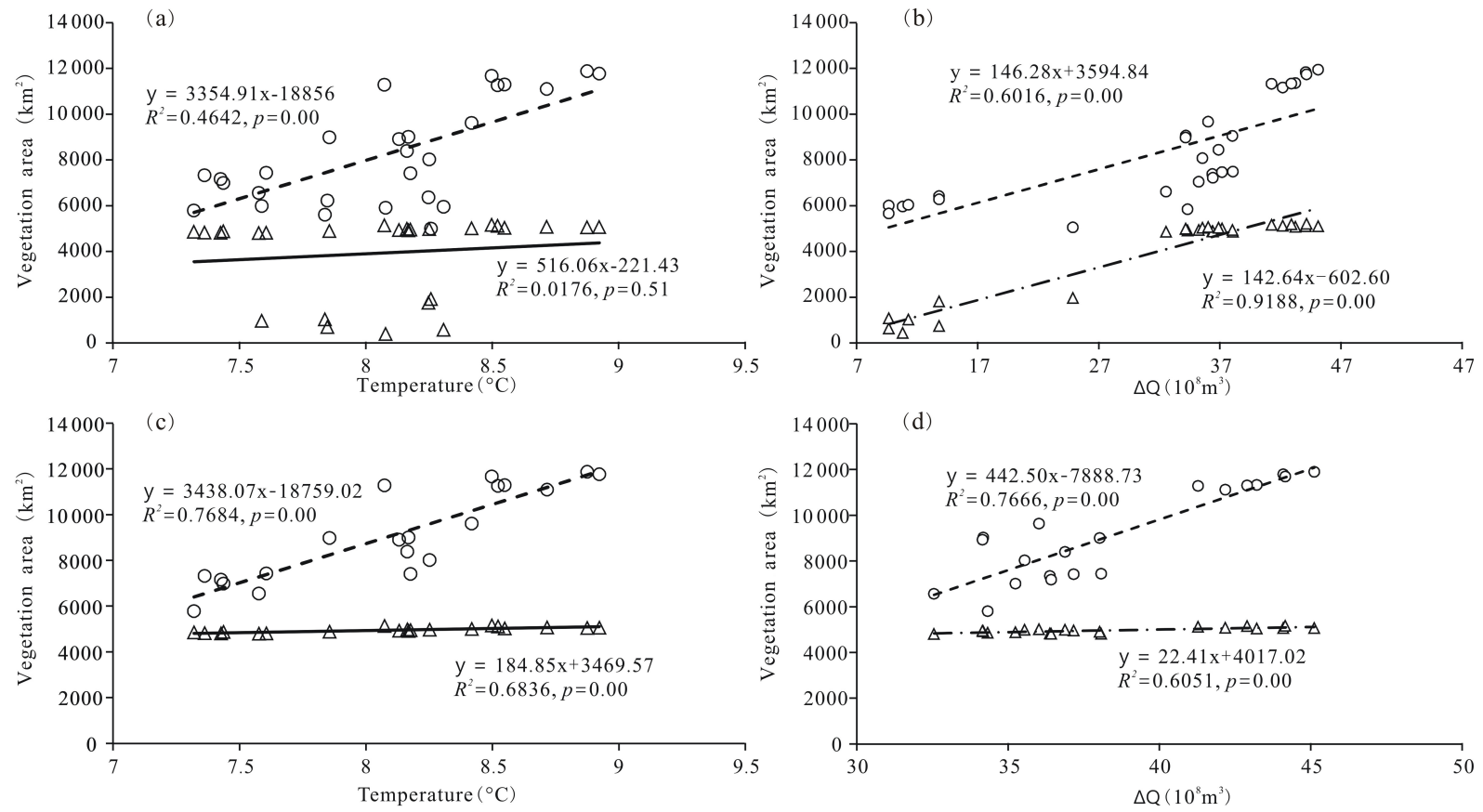

Figure 7. Correlation between vegetation (circle: natural vegetation; triangle: crops) and $T$ (a, c) and $\Delta Q$ (b, d). (a) and (b) presented all reconstructed data for the past 2000 years; (c) and (d) only used Landsat-derived estimations.

tion system or through water leakage from crop irrigation areas. However, vegetation in the lower reaches did not show synchronous development. Obviously, overuse of water in the middle reaches was the primary contributor, which is consistent with the existing literature (Nian et al., 2017; Zhao et al., 2016; Cheng, 2002; Wang et al., 2007).

Since 2000 (the post-development stage), crop vegetation distribution has slightly increased, but natural vegetation has experienced a relatively faster increase. This could be attributed to two major reasons. The first is the elevated temperature and increased streamflow provided sufficient water for both crop and natural vegetation development; this could be evidenced by their significant relationship with both natural and crop vegetation areas (Fig. 7c and d). The second is owing to the implementation of the water reallocation policy which aimed to secure water supply to the lower course of the basin to avoid ecosystem degradation.

There was a much faster increase in crop biomass than that of natural vegetation since 1949 (Fig. 6). The average biomass of crop per unit area increased by $180 \%$, while the biomass of natural vegetation did not change considerably. Lu et al. (2015b) also found that the agricultural water productivity increased by 6 times in the past 50 years in the middle reach of the HRB. This is due to technological progress on agriculture and water application. After 1949, especially after reform and opening of the national economy in the late 1980s, there were great improvements in irrigation, crop varieties, chemical fertilizers and pesticides, and mechanization in the HRB. Technological improvement influences the relationship between crop and natural vegetation. Ad- 


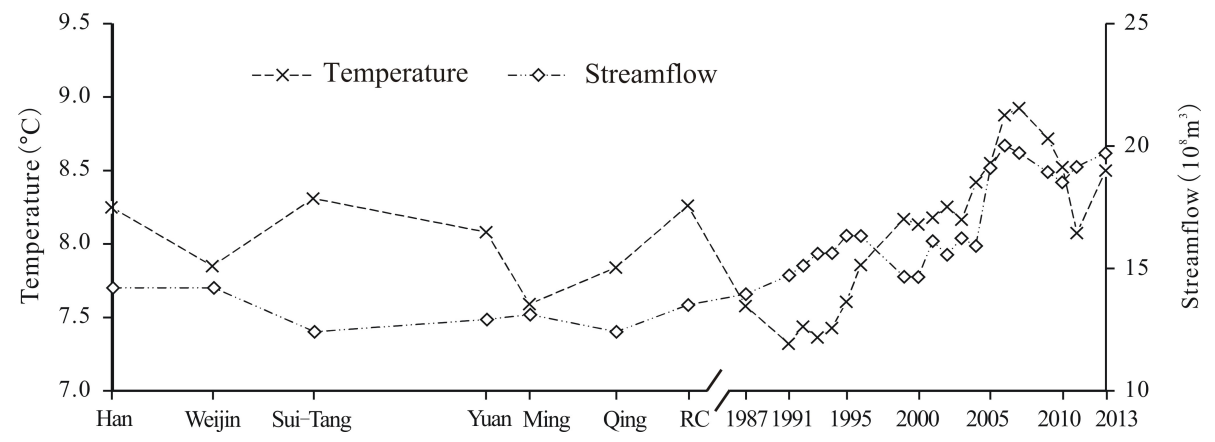

Figure 8. Temporal variations in temperature $\left({ }^{\circ} \mathrm{C}\right)$ and streamflow $\left(10^{8} \mathrm{~m}^{3}\right)$.

vances in agricultural and water technologies enabled more crop biomass without the increase in crop area and facilitated the transfer of water from agriculture to downstream ecological purposes without compromise of the middle stream economic benefit.

The total vegetation area in the HRB has increased by $8732 \mathrm{~km}^{2}$ in the past 2000 years. Crop and natural vegetation presented different evolutionary patterns (Figs. 3 and 4) and the ratio of natural vegetation to crop vegetation ranged from 16 during the Yuan Dynasty to about 2.2 since 2005 (Fig. 5). It was the result of the increase in (1) human water demand from agriculture and urban development, (2) agricultural and water technological development for improving crop biomass, (3) water allocation for the environment (terminal lake) and (4) temperature and upstream runoff. Any changes in these factors will bring about change in the ratio of natural vegetation to crop vegetation. This ratio represents the land and water development at river basin scale at changing climate and social-economic conditions. Thus, it could be used as an indicator of water and land management for better balance between the human and natural systems in river basins (Zhou et al., 2015).

Finally, some limitations in our study need to be acknowledged. Seven ancient periods were studied to track the longterm vegetation dynamics, where the short-lived Sui Dynasty (AD 581-617) was combined with the Tang Dynasty. However, some periods that documented human activities were not included in the current study due to a lack of data. For instance, the Xixia Dynasty ruled the area for more than 150 years (AD 1038-1227) and prosperous human activities were recorded which might cause substantial changes to both crop and natural vegetation. The existing literature reported crop distribution in the lower reaches of the HRB in Xixia using archaeological methods ( $\mathrm{Hu}$ and $\mathrm{Li}, 2014)$, but data for crop and natural vegetation covering the entire basin are lacking in both the literature and historical documents. Meanwhile, there was also an inconsistency between the reconstructed historic vegetation distribution and remotesensing-based extractions. For reconstruction periods, priority was given to the riverside regions, while vegetation in remote areas was less discussed, whereas for modern periods, remotely sensed images captured comprehensive vegetation distribution in all regions. Moreover, more research is needed to develop an understanding of the mechanism of dynamic interaction between natural vegetation and crop vegetation.

Data availability. The satellite imagery used in this study is available at http://earthexplorer.usgs.gov/. The runoff observation data at Zhengyixia and Juyan Lake, the groundwater recharge data, the meteorological observation data, and the Land cover maps are all available at WestDC database (http://westdc.westgis.ac.cn/).

Competing interests. The authors declare that they have no conflict of interest.

Acknowledgements. This project is supported by the National Natural Science Foundation of China (nos. 41301036, 41501464, and 91625103), the Natural Science Foundation of Jiangsu Province, China (BK20130996), and the Australian Research Council (project no. FT130100274).

Edited by: Dominic Mazvimavi

Reviewed by: two anonymous referees

\section{References}

Ahlström, A., Raupach, M. R., Schurgers, G., Smith, B., Arneth, A., Jung, M., Reichstein, M., Canadell, J. G., Friedlingstein, P., Jain, A. K., Kato, E., Poulter, B., Sitch, S., Stocker, B. D., Viovy, N., Wang, Y. P., Wiltshire, A., Zaehle, S., and Zeng, N.: The dominant role of semi-arid ecosystems in the trend and variability of the land $\mathrm{CO}_{2}$ sink, Science, 348, 895-899, https://doi.org/10.1126/science.aaa1668, 2015.

Beuchle, R., Grecchi, R. C., Shimabukuro, Y. E., Seliger, R., Eva, H. D., Sano, E., and Achard, F.: Land cover changes in the Brazilian Cerrado and Caatinga biomes from 1990 to 2010 based on a systematic remote sensing sampling approach, Appl.Geogr., 58, 116-127, https://doi.org/10.1016/j.apgeog.2015.01.017, 2015 
Cheng, G.: Study on the sustainable development in the Heihe River watershed from the view of ecological economics, J. Glaciol. Geocryol., 24, 335-343, 2002.

Esteban, E. and Albiac, J.: Groundwater and ecosystems damages: Questioning the Gisser-Sánchez effect, Ecol. Econ., 70, 20622069, https://doi.org/10.1016/j.ecolecon.2011.06.004, 2011.

Feng, X., Fu, B., Lu, N., Zeng, Y., and Wu, B.: How ecological restoration alters ecosystem services: an analysis of carbon sequestration in China Loess Plateau, Scient. Rep., 3, 2846, https://doi.org/10.1038/srep02846, 2013.

Fu, L., Zhang, L., and He, C.: Analysis of Agricultural Land Use Change in the Middle Reach of the Heihe River Basin, Northwest China, Int. J. Environ. Res. Publ. Health, 11, 2698-2712, https://doi.org/10.3390/ijerph110302698, 2014.

$\mathrm{Hu}, \mathrm{N}$. and $\mathrm{Li}, \mathrm{X}$.: Spatial distribution of an ancient agricultural oasis in Juyan, northwestern China, Front. Earth Sci., 8, 338350, https://doi.org/10.1007/s11707-014-0452-9, 2014

Huang, G., Qin, X., He, L., Zhang, H., Li, Y., and Li, Z.: Nonstationary desertification dynamics of desert oasis under climate change and human interference, J. Geophys. Res.-Atmos., 120, 11878-11888, https://doi.org/10.1002/2015JD023826, 2015.

Ian, M. F. and Reed, M. M.: Human impacts on terrestrial hydrology: climate change versus pumping and irrigation, Environ. Res. Lett., 7, 1-8, https://doi.org/10.1088/17489326/7/4/044022, 2012.

Kefi, S., Rietkerk, M., Alados, C. L., Pueyo, Y., Papanastasis, V. P., ElAich, A., and de Ruiter, P. C.: Spatial vegetation patterns and imminent desertification in Mediterranean arid ecosystems, Nature, 449, 213-217, https://doi.org/10.1038/nature06111, 2007.

Lan, Y., Ding, Y., and Kang, E.: Variations and Trends of Temperature and Precipitation in the Mountain Drainage Basin of the Heihe River in Recent 50 Years, Plateau Meteorol., 23, 724-727, 2004.

Leggett, K., Fennessy, J., and Schneider, S.: Does land use matter in an arid Environment? A case study from the Hoanib River catchment, north-western Namibia, J. Arid Environ., 53, 529543, https://doi.org/10.1006/jare.2002.1066, 2003.

Li, X., Xiao, D., He, X., Chen, W., and Song, D.: Evaluation of landscape changes and ecological degradation by GIS in arid regions: a case study of the terminal oasis of the Shiyang River, northwest China, Environ. Geol., 52, 947-956, https://doi.org/10.1007/s00254-006-0536-2, 2007.

Lowry, D. P. and Morrill, C.: Changes in the Global Hydrological Cycle: Lessons from Modeling Lake Levels at the Last Glacial Maximum, American Geophysical Union, Fall Meeting, 5-9 December 2011, San Francisco, California, USA, 2011.

Lu, Z., Wei, Y., Xiao, H., Zou, S., Xie, J., Ren, J., and Western, A.: Evolution of the human-water relationships in the Heihe River basin in the past 2000 years, Hydrol. Earth Syst. Sci., 19, 22612273, https://doi.org/10.5194/hess-19-2261-2015, 2015a.

Lu, Z., Wei, Y., Xiao, H., Zou, S., Ren, J., and Lyle, C.: Tradeoffs between midstream agricultural production and downstream ecological sustainability in the Heihe River basin in the past half century, Agr. Water Manage., 152, 233-242, https://doi.org/10.1016/j.agwat.2015.01.022, 2015 b.

Lu, Z., Xiao H., Wei, Y., Zou, S., Ren, J., and Zhang, Z.: Advances in the study on the human-water-ecology evolution in the past two thousand years in Heihe River Basin, Adv.
Earth Sci., 30, 396-406, https://doi.org/10.11867/j.issn.10018166.2015.03.0396, 2015c.

Mi, L., Xiao, H., Zhu, W., Li, J., Xiao, S., and Li, L.: Dynamic variation of the groundwater level in the middlereaches of the Heihe River during 1985-2013, J. Glaciol. Geocryol., 37, 461469, 2015.

Nian, Y. Y., Li, X., and Zhou, J.: Landscape changes of the Ejin Delta in the Heihe River Basin in Northwest China from 1930 to 2010, Int. J. Remote Sens., 38, 537-557, https://doi.org/10.1080/01431161.2016.1268732, 2017.

Pettorelli, N., Vik, J. O., Mysterud, A., Gaillard, J. M., Tucker, C. J., and Stenseth, N. C.: Using the satellite-derived NDVI to assess ecological responses to environmental change, Trends Ecol. Evol., 20, 503-510, https://doi.org/10.1016/j.tree.2005.05.011, 2005.

Pinsky, M. L. and Fogarty, M.: Lagged social-ecological responses to climate and range shifts in fisheries, Climatic Change, 115, 883-891, https://doi.org/10.1007/s10584-012-0599-x, 2012.

Ramankutty, N. and Foley, J. A.: Estimating historical changes in global land cover: Croplands from 1700 to 1992, Global Biogeochem. Cy., 13, 997-1027, https://doi.org/10.1029/1999GB900046, 1999.

Sakai, A., Inoue, M., Fujita, K., Narama, C., Kubota, J., Nakawo, M., and Yao, T.: Variations in discharge from the Qilian mountains, northwest China, and its effect on the agricultural communities of the Heihe basin, over the last two millennia, Water Hist., 4, 177-196, https://doi.org/10.1007/s12685-012-0057-8, 2012.

Sivapalan, M., Savenije, H. H. G., and Blöschl, G.: Sociohydrology: A new science of people and water, Hydrol. Process., 26, 12701276, https://doi.org/10.1002/hyp.8426, 2012.

Su, Y. Z., Zhao, W. Z., Su, P. X., Zhang, Z. H., Wang, T., and Ram, R.: Ecological effects of desertification control and desertified land reclamation in an oasis-desert ecotone in an arid region: A case study in Hexi Corridor, northwest China, Ecol. Eng., 29, 117-124, https://doi.org/10.1016/j.ecoleng.2005.10.015, 2007.

Thevs, N., Peng, H., Rozi, A., Zerbe, S., and Abdusalih, N.: Water allocation and water consumption of irrigated agriculture and natural vegetation in the Aksu-Tarim river basin, Xinjiang, China, J. Arid Environ., 112, 87-97, https://doi.org/10.1016/j.jaridenv.2014.05.028, 2015.

Turner, B. L., Lambin, E. F., and Reenberg, A.: The emergence of land change science for global environmental change and sustainability, P. Natl. Acad. Sci. USA, 104, 20666-20671, https://doi.org/10.1073/pnas.0704119104, 2007.

Wang, J. F., Cheng, G. D., Gao, Y. G., Long, A. H., Xu, Z. M., Li, X., Chen, H., and Barker, T.: Optimal Water Resource Allocation in Arid and Semi-Arid Areas, Water Resour. Manage., 22, 239258, https://doi.org/10.1007/s11269-007-9155-2, 2007.

Wang, Y., Xiao, H., and Lu, M.: Analysis of water consumption using a regional input-output model: Model development and application to Zhangye City, Northwestern China, J. Arid Environ., 73, 894-900, https://doi.org/10.1016/j.jaridenv.2009.04.005, 2009.

Xiao, S. and Xiao, H.: Advances in the study of the water regime process and driving mechanism in the Heihe River basin, Adv. Earth Sci., 23, 748-755, 2008.

Xie, Y.: Dataset of cultivated oasis distribution in the Heihe River Basin during the historical period, Heihe Plan Science Data Cen- 
ter, Lanzhou, China, https://doi.org/10.3972/heihe.092.2013.db, 2013.

Xie, Y., Wang, X., Wang, G., and Yu, L.: Cultivated land distribution simulation based on grid in middle reaches of Heihe River basin in the historical periods, Adv. Earth Sci., 28, 71-78, 2013.

Xie, Y., Wang, G., Wang, X., and Fan, P.: Assessing the evolution of oases in arid regions by reconstructing their historic spatiotemporal distribution: a case study of the Heihe River Basin, China, Front. Earth Sci., 1-14, https://doi.org/10.1007/s11707016-0607-y, 2016.

Xue, X., Liao, J., Hsing, Y., Huang, C., and Liu, F.: Policies, Land Use, and Water Resource Management in an Arid Oasis Ecosystem, Environ. Manage., 55, 1036-1051, https://doi.org/10.1007/s00267-015-0451-y, 2015.

Yang, B., Braeuning, A., Johnson, K. R., and Shi, Y.: General characteristics of temperature variation in China during the last two millennia, Geophys. Res. Lett., 29, 38-1-38-4, https://doi.org/10.1029/2001GL014485, 2002.

Yang, W., Khanna, M., Farnsworth, R., and Onal, H.: Integrating economic, environmental and GIS modeling to target cost effective land retirement in multiple watersheds, Ecol. Econ., 46, 249267, https://doi.org/10.1016/S0921-8009(03)00141-1, 2003.
Zhao, W., Chang, X., He, Z., and Zhang, Z.: Study on vegetation ecological water requirement in Ejina Oasis, China Earth Sci., 50, 121-129, https://doi.org/10.1007/s11430-007-2035-z, 2007.

Zhao, W., Niu, Z., Chang, X., and Li, S.: Water consumption in artificial desert oasis based on net primary productivity, China Earth Sci., 53, 1358-1364, https://doi.org/10.1007/s11430-0104028-6, 2010.

Zhao, Y., Wei, Y. P., Li, S. B., and Wu, B. F.: Downstream ecosystem responses to middle reach regulation of river discharge in the Heihe River Basin, China, Hydrol. Earth Syst. Sci., 20, 4469 4481, https://doi.org/10.5194/hess-20-4469-2016, 2016.

Zhou, S., Huang, Y., Wei, Y., and Wang, G.: Socio-hydrological water balance for water allocation between human and environmental purposes in catchments, Hydrol. Earth Syst. Sci., 19, 37153726, https://doi.org/10.5194/hess-19-3715-2015, 2015. 